\title{
Erwiederung über die im Octoberhefte enthaltene Kritik meiner Notizen von 0. Koch in Stade; \\ von
}

J. H. Schwacke in Alfeld.

Ich bin dem Herrn Verfasser der kritischen Bemerkungen dankbar, da ich jeden Irrthum meinerseits gern anerkenne. Als ich die Notizen schrieb, lag mir gerade der Mohr'sche Commentar von 1848 vor, und da sind denn allerdings Bd. 1. S. 346 nur 2 Unzen Cantharidenpulver zum Empl. canth. vorgeschrieben. Diese Zahl ist also ein Druckfebler, welcher aber im Druckfehler-Verzeichnisse uibersehen worden. Dass eine geringere Menge Canthariden noch wirksam sein könne, stelle ich nicht in Abrede, ich kenne Aerzte, die absichtlich 1 Th. Empl. canth. mit 8 Th. Cerat. citrin. verdünnen, um eben eine geringere Wirkung zu erzielen. Dass ich aber die Klagen des Herrn Oswald mit jener bedeutend geringeren Menge Cantharidenpulver begründet fand, war wenigstens ein ganz logischer Schluss. Jene müssen also auch erforscht werden.

Die Aerzte, mit denen ich zu thun gehabt, sind mit der Wirkung unserer narkotischen Extracte vollkommen zufrieden gewesen. Ich will gern zugeben, dass die preussischen narkotischen Extracte noch stärker sein können, welche Stärke aber auch der Geldbeutel der leidenden Menschheit unnöthig buissen muss. Mein Urtheil iiber Elect. e senna und Inf. sennae comp. kann ich nicht aufgeben. Das letztere Getränk ist seit Jahren ein tägliches Beduirfniss für Jung und Alt und hat sich ein beliebtes Biirgerrecht erworben. Die Vorschrift muss also nichts zu wuinschen übrig lassen. Es ist nicht allein der von Herrn $\mathrm{Koch}$ in Frage gestellte Korinthenzusatz, sondern der vorgeschriebene Tart. dep., welcher das Getränk so lieblich macht. Eine Auflösung ron Nanna im SennesblätterAufgusse ist, wenigstens in der Form von Syrup. mannae. das beliebteste Mittel für das zarteste Kindesalter. Das Fullen verschiedener Fluissigkeiten auf Flaschen, Einfassen 
284 Schwacke, Erwiederung über die Krilik seiner Nolizen.

von Pulver, Salzen, Extracten etc. in kleine Gläser, Appertsche Methode, Temperatur u. s. w. sind die zuverlässigen Mittel der Haltbarkeit für viele Dinge und diese sind auch bei Inf. sennae mit Erfolg anzuwenden. Was die Sapo med. betriff, so muss ich hervorheben, dass unsere Sapo med. Glycerin enthält und eben dadurch ein ganz anderes Mittel ist und sein soll, als die Preussische Seife. Es wird Herrn Koch doch nicht unbekannt sein, dass manche Aerzle geradezu Sapo med. als Vehikel zu Pillenmassen vorschreiben, dass diese aber da nicht in Anwendung kommen kann, wo sie Zersetzung bewirken würde, versteht sich von selbst. Bei der nothwendigen Wahl eines Vehikels dürte die Indifferenz der Sapo wohl nicht mehr verschlagen, als die eines Extractes, da gerade hier eine geringe Mlenge viel leistet. Ich habe auch nur rebellische Massen hervorgehoben. Dass die Vorschriften mehrerer chemischer Präparate der Hannov. Pharmakopöe eine Verbesserung erfahren müssen, ist schon hin und wieder in diesem Archive gesagt worden und komml auch zur Ausfiubrung. Die Ansichten über Vorzuige gewisser Vorschriften sind allerdings individuell verschieden und muss man am Ende Jedem die seine lassen. 